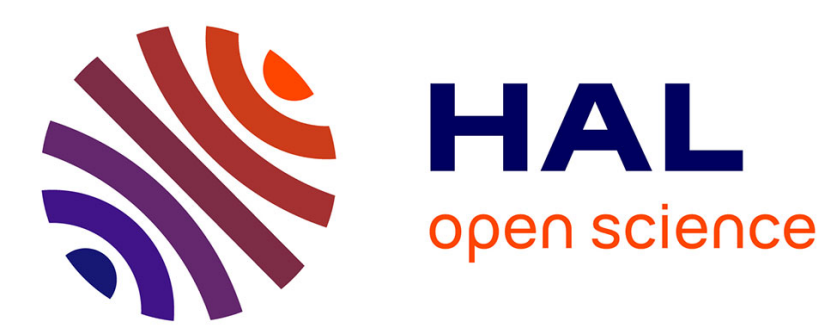

\title{
On the use of CMN thermometry in specific heat measurements below $10 \mathrm{mK}$
}

\author{
W.P. Halperin
}

\section{To cite this version:}

W.P. Halperin. On the use of CMN thermometry in specific heat measurements below $10 \mathrm{mK}$. Journal de Physique Lettres, 1979, 40 (15), pp.373-375. 10.1051/jphyslet:019790040015037300 . jpa00231647

\section{HAL Id: jpa-00231647 https://hal.science/jpa-00231647}

Submitted on 1 Jan 1979

HAL is a multi-disciplinary open access archive for the deposit and dissemination of scientific research documents, whether they are published or not. The documents may come from teaching and research institutions in France or abroad, or from public or private research centers.
L'archive ouverte pluridisciplinaire HAL, est destinée au dépôt et à la diffusion de documents scientifiques de niveau recherche, publiés ou non, émanant des établissements d'enseignement et de recherche français ou étrangers, des laboratoires publics ou privés. 


\title{
On the use of CMN thermometry in specific heat measurements below $10 \mathrm{mK}\left({ }^{*}\right)$
}

\author{
W. P. Halperin $(* *)$ \\ Department of Physics, Northwestern University, Evanston, Illinois 60201, U.S.A. \\ (Reçu le 30 mai 1979, accepté le 12 juin 1979)
}

\begin{abstract}
Résumé. - Nous remarquons que de faibles déviations de l'échelle de température du nitrate de magnésium et cérium $(\mathrm{CMN})$ par rapport à l'échelle thermodynamique peuvent donner lieu à des erreurs non négligeables en relation avec l'interprétation des mesures de chaleur spécifique basées sur la thermométrie CMN. En réinterprétant les conclusions énoncées par Hebral et al. [1] concernant le comportement anormal de la chaleur spécifique du ${ }^{3} \mathrm{He}$ solide en fonction de la température, nous montrons que toutes les données expérimentales actuellement disponibles sont en accord qualitatif.
\end{abstract}

\begin{abstract}
It is pointed out that small deviations of the cerium magnesium nitrate (CMN) temperature scale from the thermodynamic one, may give rise to significant errors in interpretation of specific heat measurements performed with $\mathrm{CMN}$-based thermometry. On reassessing the conclusions reached by Hebral et al. [1] concerning the anomalous low temperature dependence of the specific heat of solid ${ }^{3} \mathrm{He}$ it is found that all presently available data are in qualitative agreement.
\end{abstract}

A number of years ago the thermodynamic properties of solid ${ }^{3} \mathrm{He}$ were found to have anomalous behaviour at low pressures and low temperatures which produced a bit of a quandry for the theoretical description of this nuclear magnet above its transition to magnetic order at $1.1 \mathrm{mK}$. However, several models have been proposed since then and there is now a fair amount of activity in this area. Some of these theories include multiple exchange [2,3], theories invoking ground-state-vacancies [4] and polarons [5], and a lattice distortion assisted magnetic interaction [6]. New solid ${ }^{3} \mathrm{He}$ specific heat measurements by Hebral et al. [1] using a cerium magnesium nitrate (CMN) thermometer suggest that the anomalous behaviour in the specific heat may in fact be absent. It is the purpose of this note to draw attention to the cautions which are in order when using CMN thermometry at low temperatures and in particular in the measurement of the specific heat.

There is a continuing need to establish a thermodynamic temperature scale below $0.1 \mathrm{~K}$, sufficiently convenient and accessible to different laboratories

$\left.{ }^{*}\right)$ Work supported in part by the National Science Foundation through Grant no. DMR 78-11660, and the Alfred P. Sloan Foundation.

(**) Alfred P. Sloan fellow. such as to provide a common basis for thermodynamic measurements. This point has been underscored by the considerable experimental efforts that have stemmed from the discoveries of the ${ }^{3} \mathrm{He}$ superfluid phases and the transition to magnetic order in solid ${ }^{3} \mathrm{He}$ below $3 \mathrm{mK}$. Of the three or four temperature scales which may be considered thermodynamic perhaps the most convenient in its applicability is the pressure-temperature relation of the ${ }^{3} \mathrm{He}$ melting curve [7]. It has been shown [7] that this $P-T$ relation can be established through application of the second law of thermodynamics and measurements of the latent heat of solidification of ${ }^{3} \mathrm{He}$. Two more recent thermometry techniques based on ${ }^{195} \mathrm{Pt}$ nuclear magnetic resonance [8] and the susceptibility of La diluted CMN [9] appear to give results consistent with the melting curve scale. At the time that the melting curve work was done an attempt was made [7] to relate this new temperature scale to that of CMN, which was then the prevalent thermometric technique. Specifically there was a need to intercompare measurements of the heat capacity of liquid ${ }^{3} \mathrm{He}$ obtained with these two different thermometries. It was found at the time that some of the differences between the two heat capacities could be attributed to this thermometry interrelation. A similar conclusion is drawn here about the reported difference between the solid 
${ }^{3} \mathrm{He}$ specific heat measurements of Hebral et al. [1] using CMN thermometry, and that of either Halperin et al. [7], performed on the melting curve, or Dundon and Goodkind [10], which employed $\mathrm{Cu}$ NMR thermometry.

Historically, a good representation of the magnetic CMN temperature, $T^{*}$, has been $T^{*}=T-a$ where $T^{*} \equiv C / \chi, T$ is the thermodynamic temperature, $C$ is the Curie constant, $\chi$ is the temperature dependent susceptibility, and $a$ is a constant.

A considerable amount of work with different CMN thermometers has been done and is reviewed by Wheatley [11]. Principally, it is found that the above relation breaks down at temperatures below 4 or $5 \mathrm{mK}$. At low temperatures $T^{*}=T-a+f(T)$, where the temperature dependent function $f(T)$ becomes of the order of $1 \mathrm{mK}$ at $T=2 \mathrm{mK}$. It has been noted by Wheatley [11] that, whereas the constant $a$ may vary considerably from one thermometer to another, the function $f(T)$ is the same to better than $20 \mu \mathrm{K}$ for each CMN thermometer (rightcircular cylinder, diameter equal to height). This suggests that $f(T)$ depends predominantly on the spin-spin interactions in the CMN.

Taking a high-temperature series expansion of the partition function one derives a series expansion for the temperature dependent susceptibility,

$$
\chi=\frac{C}{T}\left[1+\frac{a}{T}+\frac{b}{T^{2}}+\cdots\right] \equiv \frac{C}{T^{*}}
$$

from which $f(T)=-\frac{b}{T}+\cdots$ and thus the new $T-T^{*}$ relation would be in leading order,

$$
T^{*}=T-a-b / T .
$$

In following this line of argument we have intercompared measurements of the $P-T^{*}$ [12] relation with that of the melting curve temperature scale [7], $P-T$. This results in a good fit to the above relation with $b=1.5 \mathrm{mK}^{2}$. In order to determine the coefficient $a$ for each thermometer it is sufficient to have one fixed point. It is very convenient to take the superfluid transition $T_{\mathrm{A}}=2.75 \mathrm{mK}$ on the melting curve [7] as such a point since it can be precisely identified by the large liquid ${ }^{3} \mathrm{He}$ heat capacity discontinuity at this temperature.

An independent assessment of the $T-T^{*}$ relation comes from a temperature scale developed at $\mathrm{La}$ Jolla [9] which assumes that the attenuation of zero sound in normal liquid ${ }^{3} \mathrm{He}$ varies as $T^{2}$. This comparison [7] gives the same value of $b$ as above.

Detailed magneto-thermodynamic measurements performed on a single crystal sphere of CMN by Fisher et al. [13] give the CMN susceptibility in terms of a self-consistent thermodynamic temperature. From an extrapolation of high temperature data they find $a=-0.75 \pm 0.1 \mathrm{mK}$. At lower temperatures $(T<6 \mathrm{mK})$ their work is in qualitative agreement with the proposed modified $T-T^{*}$ relation where at $4 \mathrm{mK}, b=1.7 \pm 0.4 \mathrm{mK}^{2}$.

In applying this to the CMN-based thermometry measurements of the liquid ${ }^{3} \mathrm{He}$ specific heat, $C_{1}$, which is approximately proportional to the temperature, we find that,

$$
\frac{\Delta Q}{\Delta T^{*} T^{*}} \simeq \frac{C_{1}}{T}\left[1+\frac{a}{T}+\frac{a b}{T^{3}}+\frac{b^{2}}{T^{4}}\right] .
$$

For each thermometer it is very useful to measure $T_{A}^{*}$ in order to determine one fixed point of the $T-T^{*}$ relation. In the work of Abel et al. [14] this was not done, but Mota et al. [15] estimate $a \lesssim 0.2 \mathrm{mK}$, whence it is found that the ratio $C_{1} T^{-1}$, which determines the ${ }^{3} \mathrm{He}$ quasi-particle effective mass by proportionality, may be in error by as much as $6 \%$.

For the case of solid ${ }^{3} \mathrm{He}$, which in fact stimulated this discussion, the specific heat, $C_{\mathrm{s}}$, is expected to be proportional to $T^{-2}$ in leading order

$$
C_{\mathrm{s}} T^{2}=3\left(\frac{J_{x x}}{k_{\mathrm{B}}}\right)^{2}-3\left(\frac{J_{x x x}}{k_{\mathrm{B}}}\right)^{3} \frac{1}{T}+\cdots,
$$

where the coefficients $J_{x x}$ and $J_{x x x}$ are moments of the exchange Hamiltonian [3, 7]. It was found in the work of Halperin et al. [7] and Dundon and Goodkind [10] that $\left|J_{x x}\right| \simeq\left|J_{x x x}\right|$ but that $J_{x x x}$ was positive, contrary to expectation. This data ruled out the possibility of a simple near-neighbour, pair-exchange, description of ${ }^{3} \mathrm{He}$ solid below $10 \mathrm{mK}$. However, the recent heat capacity measurements of Hebral et al. [1] indicate that $\left|J_{x x x}\right|$ is as much as five times smaller than that determined by the earlier work. This result lifts a significant constraint placed upon the theoretical models. Since this work uses CMNbased thermometry we use the modified $T-T^{*}$ relation to find,

$$
\frac{\Delta Q}{\Delta T^{*} T^{* 2}}=C_{\mathrm{s}} T^{2}\left[1-\frac{2 a}{T}+\frac{a^{2}-3 b}{T^{2}}+\cdots\right] .
$$

Fortunately, Hebral et al. [1] measured $T_{A}^{*}$ giving $T_{\mathrm{A}}-T_{\mathrm{A}}^{*}=0.5 \mathrm{mK}$ which determines

$$
a=-0.03 \mathrm{mK} \text {. }
$$

Combining this with $b=1.5 \mathrm{mK}^{2}$ in the above relation, we obtain a suggested adjustment to their heat capacity results plotted in the figure 1 amounting to as much as $20 \%$ at $4 \mathrm{mK}$. Also shown are the results of Dundon and Goodkind [10] for a number of solid ${ }^{3} \mathrm{He}$ densities and the heat capacity deduced from measurements of the solid ${ }^{3} \mathrm{He}$ entropy on the melting curve [7]. These are adjusted where necessary to a common molar volume of $23.8 \mathrm{~cm}^{3} /$ mole using the following procedure. A number of measurements at high temperatures $(T>10 \mathrm{mK})$ indicate [3] that $\mathrm{d} \ln J_{x x} / \mathrm{d} \ln v=18$ where $v$ is the molar volume, for which $C_{\mathrm{s}} \propto v^{36}$. In adjusting the data to

$$
v=23.8 \mathrm{~cm}^{3} / \mathrm{mole}
$$




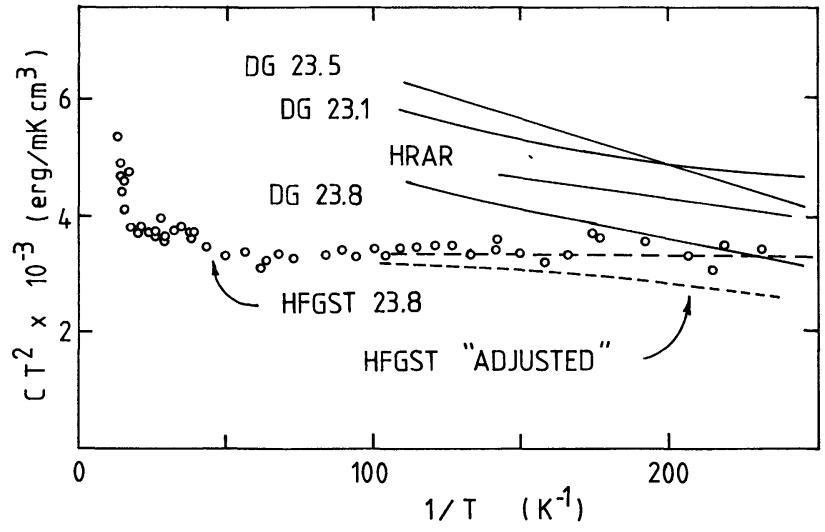

Fig. 1. - Specific heat of solid ${ }^{3} \mathrm{He}$ in the form $C T^{2}$ versus the inverse temperature $T^{-1}$. The data of Hebral et al. [1] are shown (HFGST) as well as the suggested effect on this data of an adjustment for deviations of CMN temperature from the thermodynamic temperature. The data of Dundon and Goodkind [10] for three molar volumes (DG 23.1, DG 23.5, DG 23.8) are represented, scaled to the same molar volume $23.8 \mathrm{~cm}^{3} / \mathrm{mole}$. The melting curve entropy measurements [7] HRAR are shown adjusted to the molar volume $23.8 \mathrm{~cm}^{3} /$ mole. it is assumed that this behaviour continues below $10 \mathrm{mK}$.

Although differences remain in absolute values between the data sets it is clear that all the slopes of the graphs at low temperatures are negative. Consequently all data appear to be consistent with an anomalous behaviour of the specific heat in the sense that $J_{x x x}$ is large and positive. The existence of a discrepancy in $J_{x x}^{2}$ may reflect the very strong dependence of the specific heat on density through possible inaccuracies in measurement of the molar volume or a deviation of the density dependence of the specific heat from that which was assumed. Accurate measurements of the specific heat as a function of temperature and density below $10 \mathrm{mK}$ will be helpful in elucidating this question.

Acknowledgments. - Communications with A. S. Greenberg and B. Hebral are gratefully acknowledged.

\section{References}

[1] Hebral, B., Frossati, G., Godfrin, H., Schumacher, G. and Thoulouze, D., J. Physique Lett. 40 (1976) 41.

[2] McMahan, A. K., Wilkins, J. W., Phys. Rev. Lett. 35 (1975) 376.

[3] GuYer, R. A., J. Low Temp. Phys. 30 (1978) 1.

[4] Sokoloff, J. B. and Widom, A., Phys. Rev. Lett. 35 (1975) 673.

[5] Heritier, H. and Lederer, P., J. Physique Colloq. 39 (1978) C6-130.

[6] Papoular, M., J. Low Temp. Phys. 31 (1978) 595.

[7] Halperin, W. P., Rasmussen, F. B., Archie, C. N. and Richardson, R. C., J. Low Temp. Phys. 31 (1978) 617, and references therein.

[8] Avenel, O., Bernier, M., Bloyet, D., Piejus, P., Varoquaux, E. and ViBeT, C., Proc. of the 14th Int. Conf. on Low Temp. Phys. (North-Holland, Amsterdam) 1975, vol. 4, p. 64 .
[9] Paulson, D. N., Krusius, M., Wheatley, J. C., Safrata, R. S., Kolac, M., Tethal, T., Svec, K. and Matas, J., J. Low Temp. Phys. 34 (1979) 63.

[10] Dundon, J. M., Goodkind, J. M., Phys. Rev. Lett. 32 (1974) 1343.

[11] Wheatley, J. C., Physica 69 (1973) 218 ; see also Paulson, D. N., Ph. D. thesis, University of California San Diego (unpublished).

[12] Johnson, R. T., Paulson, D. N., Pierce, C. B. and Wheatley, J. C., Phys. Rev. Lett. 30 (1973) 207.

[13] Fisher, R. A., Hornung, E. W., Brodale, G. E., Giauque, W. F., J. Chem. Phys. 58 (1973) 5584.

[14] Abel, W. R., Anderson, A. C., BlaCK, W. C. and Wheatley, J. C., Phys. Rev. 147 (1966) 111

[15] Mota, A. C., Platzeck, R. P., Rapp, R. and Wheatley, J. C., Phys. Rev. 177 (1969) 266 